\title{
The Education Of Culturally And Linguistically Diverse Students
}

Sunita Sharma, (E-mail: ssharma@vuu.edu), Virginia Union University

\begin{abstract}
In this study, the researcher has examined and presented the perceptions and attitudes of $K-12$ school teachers regarding students from culturally and linguistically diverse backgrounds. In addition, these same teachers were asked to evaluate their own professional preparations that might enable them to identify and effectively teach these students. This researcher conducted an in depth study in a Northwest Florida School District (Escambia Co.), and a Nodaway County School District in Missouri. A proportionate, stratified, random sample of $300 \mathrm{~K}-12$ regular education teachers, special education teachers, school counselors, and therapists was used for the survey. In addition, a case study was conducted of 30 members from each school district. The findings of these studies, plus previous research and current literature all indicate that these educators were not professionally prepared to identify, understand and work with culturally, and linguistically diverse students.
\end{abstract}

\section{INTRODUCTION}

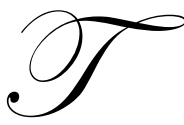

he United States of America has become a multicultural and multilingual global society where literacy teachers and teacher educators continually encounter many challenges (Xu, 2006). According to Gollnick and Chinn (2004), educators today are faced with an overwhelming task-that of teaching students from culturally and linguistically diverse backgrounds. To work effectively with such students, it is imperative that teachers understand cultural backgrounds and settings; only then will teachers be able to develop appropriate teaching and learning strategies (Sharma, 2005). Ultimately, the goal is to improve the education of these culturally diverse students, but concomitantly, teachers must inform all other students and help to sensitize them to cultural diversity (Howell, 1997).

While some writers have identified this pressing educational need, the research presented here provides actual data from a typical, discreet group of teachers. The data thus provide a model by which to accurately assess the larger situation, and thereby indicate possible directions for solving these urgent problems.

\section{WHAT TEACHERS THINK OF MULTICULTURAL EDUCATION}

Teachers' attitudes about culturally and linguistically diverse students in the nation's classrooms are the key factors in motivating, educating, and making a difference for students, regardless of gender, ethnicity, age, religion, language, or ability. The majority of teachers usually, consciously or unconsciously, exhibit biases towards students in some manner (Sharma, 2005). In addition, teaching methodologies are often different from those familiar to culturally diverse students (Gollnick \& Chinn, 1991).

According to Gay (1994), teachers think that their own values, beliefs, and actions are the standard norms, and what they know and what they teach is governed by learned principles rather than informed, and sympathetic understanding. Due to this lack of understanding, teachers can engage themselves consciously or unconsciously in "mis-education practices." Due to this failure on the part of teachers to understand, accept, and appreciate cultural and linguistic diversity, students feel that the school environment is alien and hostile towards them (Sharma (2005). Sharma further stated that this situation causes stress and anxiety that can affect students' daily, academic performance. At times, learning in a school setting is even perceived of as a high risk-taking activity for the many of 
the culturally and linguistically diverse students. All students, regardless of background, work better when they feel comfortable and emotionally secure in the school environment.

According to Costa (1997), formal education depends upon both the attitudes and the professional preparedness of teachers. It becomes all the more critical to have appropriate attitudes, perceptions and professional preparation to teach effectively in multicultural classrooms. Generally, teachers have a simplistic, romantic, or idealistic vision of multicultural education; their notions often focus on external factors or ethnic myths. Pena (1997) noted that analyses, related to teachers' perceptions, indicate that educators spend little time getting to know their students and, therefore, have very little knowledge about them. At the same time, the students from the cultural minority groups experience rejection by their teachers because of their teachers' perceptions and lack of appropriate preparation.

In formal situations, teachers knowingly deny the fact that the presence of culturally and linguistically different students causes problems (Sharma (2005). However, in informal conversations, the same teachers provide negative and conflicting stories about minority students. For example, they complain that these students have language deficits for which the teachers have to compensate. In terms of training, teachers are very aware that they lack professional preparation in multicultural education, and yet some of these teachers do not consider proper professional training a high priority (Ladson-Billings, 1995).

Fueyo and Bechtol (1999) investigated how teachers' perceptions influence classroom practices in three areas. (1) Teachers have low expectations of culturally and linguistically diverse students in the areas of valuing bilingualism, reading-related instructional practices, and reading-related assessment or tests. (2) Teachers with negative perceptions have a tendency to discourage linguistic minority students from using their primary language and rarely or never use bilingual materials or activities for academic purposes. (3) teachers with negative perceptions of ethnic minorities have also exhibited differential treatment towards students because of gender, appearance, or stereotypical views based upon students' last names.

\section{PREPARING TEACHERS FOR THE MULTICULTURAL CLASSROOM}

"White Americans increasingly reject racial injustice in principle, but remain reluctant to accept the measures necessary to eliminate the injustice" (Pettigrew, 1979). This insightful comment was made twenty-eight years ago, yet the problem still exists. It is only recently that other educators and theorists have attempted to address the issue. Below is an overview of some of these writers and a condensation of their observations.

Futrell, Gomez, and Bedden (2003) and National Center for Education Statistics (NCES, 2003) state that cultural and linguistic diversity in American society and classrooms pose a great challenge to educators and administrators in higher education. Hinchey (1994) reports that according to the analysis of the teacher education population, $92 \%$ of the teachers are Caucasians and $85 \%$ are from the middle socio-economic class. On the contrary, Futrell, et. al. and NCES stated that fewer than 10 to $12 \%$ of teachers and fewer than $12 \%$ of the school administrators are from ethnic minority groups. Only $6 \%$ of the teachers in the U.S. public schools are AfricanAmerican and fewer than 5\% of the teachers are from other races. According to NCES, in 2001-02, 60\% of the public school students were White, 17\% Black, 17\% Hispanic, 4\% Asian/Pacific Islander, and 1\% American Indian/Alaska Native. The trend seems to be that the number of minority teachers is in decline. This is confirmed by Bell and Munn (2000) and Wallace (2001), who states that 90\% of preservice teachers are middle-class Caucasians and a significant number of them are the first generation in their family to attend college.

Nelson (2001) emphasizes that teacher education faculty are the ones responsible for training and preparing the preservice teachers so that they have with the ability and affinity to go beyond stereotypes. This must occur with all aspects of schooling, and curriculum policies and practices. Bigler (2002), recommended that all teachers (preservice and in-service) be well trained in the history of the United States in regard to race relations and anthropology. 
The most effective teachers have learned to understand the cultures of their students, thus their students come to trust them (Schlosser, 1992). Preservice teachers need to develop awareness of their own cultural perspectives, beliefs, and behaviors, and to realize that their own cultural perspective is not universal, nor the only "right" one. Preservice teachers need to acquire multicultural competence, the ability to be functional in crosscultural settings, and to be able to interact and communicate effectively with culturally diverse students and their parents (Chisholm, 1994).

Until 1960, the majority of immigrants to the U.S. came from Europe. Between 1980 through 2002, the majority of immigrants came from Asia, Central America, and the Caribbean. Additionally, large numbers of Puerto Ricans and Mexican- Americans are the fastest growing ethnic groups in America today. By the year 2050, descendants of all nonwhite groups are expected to represent more than $40 \%$ of the American population (Parla, 1994). The United States Department of Education (1990), Office for Educational Research, indicated that between 1979 and 1989, the number of non-English speaking children between the ages of 8 and 15 increased by $41 \%$. It is evident that the number of Limited English Proficient (LEP) students and culturally diverse students is on the rise. At the same time, there is a lack of specialized multicultural training for U.S. classroom teachers (Pallas, Natiello, \& McDill, 1989).

Blackwell, Futrell and Imig (2003) stress that the turn of the 21st century has brought in a larger number of immigrants, along with a greater diversity and a greater challenge for the education system. It has become imperative to stress diversity through multicultural education. To accomplish this, some significant changes in the curricula of teacher education are needed. Blackwell et al. stress the need to include courses related to culture, linguistics, diversity, gender, race, and equity in the teacher education curriculum, in order to empower new teachers to work against those social and structural arrangements in schools and society that promote inequality.

Parla (1994) proposed three major components to prepare all teachers to instruct culturally diverse and limited English proficient students. These three components are (a) theoretical base, (b) linguistic and cultural diversity base, and (c) experimental base. The theoretical base establishes the foundation of common definitions, knowledge of issues, and self-identity upon which the trainee can build the skills to implement effectively a multicultural program. The linguistic and cultural diversity base provides the trainee with needed competencies in second language acquisition and development, knowledge of the relationship between language and culture, and an increased ability to affirm the cultures of diverse students. Cultural diversity awareness is needed to provide trainees with the knowledge of and experience with a variety of racial and ethnic groups in the United States. Limited or no experience with culturally and linguistically diverse groups in their own communities makes it more difficult for teachers to accept and affirm diversity as a part of the American mosaic.

According to Parla (1994), the experimental base enables teacher trainees to receive practical and hands-on experience with students. For success during field training, it is important that the supervising teachers are trained to become mentors in the field of multicultural education. Prospective mentors must be provided training with staff development activities to ensure their effective mentorship. Otherwise, the validity of the field training remains questionable.

\section{HOW VALUES AND ATTITUDES AFFECT EDUCATION}

Gorski (2000) strongly emphasized that teachers have a dual responsibility; one to teach, and secondly to engage in the critical and continual process of examining their own prejudices, biases, and perceptions. To be an effective multicultural, one must continue self-examination and transformation. Nelson (2001) argues that having a belief system which values racial and cultural differences is the key to improving equal opportunities for all students.

Costa (1997) states that it is necessary to approach teacher training from moral and attitudinal perspectives, along with the understanding of the implications of multicultural education from academic, methodological, and political positions. Costa further emphasizes that teacher training should learn from the past, but be a committed to the present and future. Fueyo and Bechtol (1999), also emphasized the need for respect of cultural differences and 
diversity; the teachers need to be culturally aware, competent, and above all willing to incorporate students' cultures into their classroom curricula.

Zeichner (1993) recommends that preservice teachers be interviewed before they are accepted in the teacher education program in regard to their sensitivity for cultural and linguistic diversity. During the teacher training program, preservice teachers should be taught to examine their attitudes toward other ethnic groups, to alert themselves to prejudice, racism, or lack of respect towards socioeconomic disparities. Only then can they deal with these issues in the classroom. Zeichner further asserts that preservice teachers should be informed about students' learning styles, use instructional strategies, and employ assessment procedures sensitive to their cultural and linguistic backgrounds. Student teachers should have field experience with adults and children of diverse ethnic groups with guided reflections.

\section{ADJUSTING THE CURRICULA}

Penny, Forney, and Harlee (2000) report that Florida was one of the first states to make multicultural education courses mandatory for teacher certification during the 1970s. However, teachers still lack sufficient training and resources for the implementation of relevant multicultural curricula. For example, teachers might incorporate intervention strategies, or utilize specially trained school staff, or professionals from a variety of backgrounds. Penny et al. state that many teachers around the country have not taken a single course in multicultural education, and those who have taken one or more courses are not using the knowledge in their instruction. Teachers need to understand that they can enhance the quality of education by capitalizing on all human resources.

Gay (1994) and Ladson-Billings (1994, 1995) suggest that the teacher education curriculum must develop a theoretical and practical connection between cultural relevance and the academic success. Those authors also recommend that teacher education faculty should plan to integrate diversity education into all aspects of a teacher education curriculum. The teacher education curricula should also provide preservice teachers with practical experience, and an opportunity to learn to apply diversity education and training. Munn (1996) suggests that teacher education faculty at colleges and universities should be appropriately trained in cultural diversity education to be able to teach preservice teachers to be culturally sensitive.

Wallace (2001) emphasizes the need for multicultural education in the mainstream course work for preservice teachers, who also need to involve themselves in critical reflection about the ethnic make-up of their community. According to Penny et al. (2000), it is very crucial, presently, for the teachers to learn how to be able to adapt to the constantly changing teaching environment. According to Grant, as cited in Penny et al., "there are nine principles that educators need to follow in order to provide multicultural education to the changing demographics of a multicultural society:

1. It must help students increase their academic achievement levels in all areas, including basic skills, through the use of teaching approaches and materials that are sensitive and relevant to students' socio-cultural background and experiences.

2. Attention to voice must be a part of multicultural instruction.

3. Verbal and non-verbal communication patterns between students and teachers must be analyzed to increase involvement of students in the learning process.

4. The learning styles of students and teaching style of teachers must be understood and used to develop effective instructional strategies.

5. Multicultural education must permeate the formal curriculum.

6. Multicultural education must impact the hidden curriculum at all levels.

7. Multicultural education must teach students to think critically by allowing them the freedom to ask questions and develop the tools to reason.

8. Multicultural education requires an understanding of the culture of families in the community.

9. Multicultural education must use the community as a resource" (p. 220). 
Merryfield (1995) emphasized that global knowledge and cross-culture experience must be infused throughout teacher education programs. Field experience and internships should be structured where the preservice teachers can work with talented multicultural education instructors. According to Marriott (2003), in addition to training preservice teachers in multicultural education, new teachers must be provided with the access to a trained partner, a mentor to assist in clarifying educational goals and challenges of educational curriculum.

Merryfield (1995) argues that educators need to be aware of the complexities of globalization and develop skills in multicultural education if they really want to become effective citizens and teachers in a pluralistic and interdependent world. Gorski (2000) recommends that educators, researchers, activists, and everyone else must continue to practice and apply multicultual education inside and outside of the classroom. Linguistic diversity, among other elements, must be acknowledged as an important component of multicultural education (Parla, 1994). Linguistic diversity is not a matter of individual preference, curricular accessory, or an academic whim. It should not be an "added-on" course after providing for rudimentary knowledge and skills. Multicultural education is not merely an ethnic issue. It is everyone's issue, for teaching is a multicultural experience (Chisholm, 1994).

\section{PURPOSE OF THE STUDY}

The first question of this study was to reveal teachers' attitudes towards their students, but the more relevant question was how do teachers perceive their own preparation to teach culturally diverse students? In addition, the study solicited their recommendations for training in the field of teacher education preparation programs.

\section{SIGNIFICANCE OF THE STUDY}

The very final end goal of all reported efforts is twofold: to better educate students from cultural and linguistic minorities, and secondly to inform and help sensitize other students to cultural diversity. Towards this end, this study is important in several ways. First, it provides teacher education programs with recommendations for a contemporary preservice teacher training curriculum. It provides data that document teachers' perceptions as to where and how they acquired and developed skills to teach diverse student populations. It provides information about the academic and personal demographics of teachers, and finally it provides insight into the teachers' personal ideas about multicultural education.

Second, the focus of this study is on teachers' ideas about multicultural education and teacher preparation. The recommendations and suggestions provided by the participants could benefit the teacher education programs at colleges and universities, because such programs are struggling with ideas about the best ways to prepare prospective teachers. Some insights on teaching beyond the geographical limits of the study are provided here.

Third, this study is significant because it was the first district-wide survey of public school teachers in Escambia County, Florida, and Nodaway County, Missouri, that investigated teachers' perceptions of multicultural education and their own professional preparation to teach culturally and linguistically diverse students.

\section{RESEARCH QUESTIONS}

Drawing upon the issues and concerns addressed in the literature on teacher preparation to teach culturally diverse students, this researcher asked a selected group of high school, middle school, and elementary school teachers in both the school districts to assess their perceptions concerning their professional preparation to teach culturally diverse students. This researcher also asked teachers to offer recommendations for teacher education preparation in teaching culturally diverse students. Thus, a survey was conducted to address the following questions: 
1. What are the teachers' demographic characteristics?

2. What are the teachers' perceptions concerning their professional preparation to teach culturally diverse students?

3. What relationships exist between teachers' perceptions concerning their professional preparation to teach culturally diverse students and the following demographic characteristics?

a. Ethnicity of teachers;

b. Educational level;

c. $\quad$ Years of teaching experience;

d. $\quad$ Current grade level taught;

e. $\quad$ Contact with culturally diverse students; and

f. Number of credits hours that had been taken in multicultural education.

4. With regard to methodology of teaching culturally diverse students, what suggestions are offered by the teachers (participants) for inclusion in college and university's teacher education preparation programs?

5. What responses do practicing classroom teachers provide when administered personal interviews on the following nine questions about the significance and challenges of multicultural education?
a. What is the meaning of multicultural education?
b. What is your perception of multicultural education?
c. What kind of personal experiences have affected your ideas about teaching culturally and linguistically diverse students?
d. What kind of professional experiences have affected your ideas about teaching culturally diverse students?
e. How do you perceive and deal with the prejudices of culturally diverse students?
f. How do you think that your teacher education program has prepared you to teach in a culturally diverse classroom?
g. What do you think is the significance of multicultural education?
h. What do you perceive as the challenges of multicultural education?
i. What recommendations would you suggest to college and university teacher education programs to prepare future teachers to teach culturally and linguistically diverse students?

\section{METHODOLOGY}

Qualitative and quantitative research techniques were utilized in this study. Data were gathered using a questionnaire survey and a case study. The target population was public high school, middle school, and elementary school teachers from the School District of Escambia County, Florida. Fifty teachers from each educational level were selected using a proportionate stratified random sample. The questionnaire was mailed to the selected teachers with a self-addressed, stamped return envelope. For the case study (interviews) 15 teachers were selected. Five teachers from each educational level (high school, middle school, and elementary school) were selected using a proportionate stratified random sample from the same population used for the questionnaire survey. Similar methods and surveys were used in the Nodaway school district.

\section{STATISTICAL ANALYSIS}

For Part I, on the demographic characteristics of participants such as gender, ethnicity, age, education, and years of teaching experience, grade level of student teaching, subject taught, income, significant contact with culturally diverse people, and credit courses in multicultural education questionnaire, the data were reported using descriptive statistics consisting of frequencies, percentages, and measures of central tendency. Standard deviations were used to measure variability. For Part II, on teachers' preparation and perceptions of multicultural education questionnaire, which consisted of 23 statements, descriptive statistics were used to report overall responses to the statements. 
Part III consisted of one open-ended question which allowed for personal comments and suggestions about teacher education programs for instructing culturally diverse students. The answers to this question were organized into discreet categories. A count was conducted on the number of respondents who shared comments in one or more categories regarding their evaluation of their professional preparation for teaching culturally diverse students. These categories were operationally defined. Patterns of similar comments were identified as emergent themes and several examples of responses were cited for each category

\section{CASE STUDY (INTERVIEWS)}

According to LeCompte and Preissle (1993), "case studies can be qualitative as well as quantitative. In the term case study, a case is the number of units one studies. Case study analysis is appropriate for intensive, in-depth examination of one or few aspects of a given phenomenon" (pp. 32-33). The purpose of the case study (interviews) was to gather qualitative supplemental data with maximum efficiency and minimum bias regarding the teachers' perceptions about multicultural education and their professional preparation for teaching it. These interviews allowed the interviewees to provide detailed accounts on the topic at issue. Interviews provide immediate feedback, permit the interviewee to follow up on leads, and obtain additional data to enhance clarity (Tuckman, 1999).

Interviews were conducted with 30 participants: 10 high school teachers, 10 middle school teachers, and 10 elementary school teachers. Participants were selected by proportionate, stratified, random sampling methodology from the same sample which was used for the questionnaire survey. Each of the participants was assigned a code number. Once the interviewees were selected, the researcher worked out a mutually convenient interview schedule with the interviewees. Interviews were conducted one-on-one in neutral and mutually convenient settings. Each interview lasted for approximately 30 to 45 minutes as was estimated.

Interviews were audio taped with the permission of the interviewees and later transcribed. The use of tape recorder has several advantages in recording the interview data for research. It reduces the tendency of interviewers to make an unconscious selection of data favoring their biases, and it is also possible to reanalyze the taped interview data to test hypotheses not considered in the original study. With tape-recorded data, it is possible for a person other than the interviewer to evaluate, classify, and score the responses. Tape recording allows calculation of reliability coefficient on the obtained interview data (Borg \& Gall, 1989).

\section{SUMMARY, DISCUSSION, AND RECOMMENDATIONS}

The focus of the current research was the topic of teacher preparation in teaching culturally diverse students in our nation's school system. Studying teachers' perceptions concerning their professional preparation to work with culturally diverse students, and assist the teacher education programs to prepare teachers to work more effectively with culturally diverse students. Findings from both school districts were quite similar with one significant difference. That difference was that of demographics of the teachers. Escambia school district is more urban, whereas Nodaway school district is very rural, and consists of $100 \%$ white Caucasians.

Five categories were identified from these data. The highest frequency of responses was a recommendation for more credit courses at the university in multicultural education and inclusion of multicultural topics in other courses as well. The second highest frequency of responses was recommendation for in-service workshops. The third highest frequency of responses was a recommendation that teachers have for real-life experiences with culturally diverse people. The fourth highest frequency of responses was in the category of general comments about multicultural education. In this category, participants suggested education abroad for real-life experience in developing and third world countries. The lowest frequency of responses was the recommendation for changes in overall teacher education programs at the university level.

Respondents seemed to have serious concerns about the need for training and experience in multicultural education for teachers in culturally diverse classrooms. The majority of the respondents commented on more than one category, emphasizing the need for training in multicultural education for teachers. 
What responses do practicing classroom teachers provide when administered personal interviews on the nine questions about significance and challenges of multicultural education? After transcribing the interviews from audiotape onto paper, the researcher drew conclusions for each of the nine questions answered by the 30 respondents. During interviews, teachers quite openly shared their feelings as to whether or not they were professionally prepared to teach culturally diverse students. Teachers also made strong recommendations suggesting a variety of options for training in multicultural education for those teachers and preservice teachers currently engaged in teaching. The recommendations were (a) more courses in multicultural education; (b) infusion of multicultural education across the curricula at the university; () practicum in culturally diverse classrooms; (d) inservice workshops, seminars and presentations for practicing teachers. Some of the teachers even recommended that teachers study abroad in developing and underdeveloped countries.

\section{IMPLICATIONS}

From the literature review and current findings, four major implications have emerged. These are (a) implications regarding instruments used to assess teachers' perceptions, (b) implications related to gender, (c) implications related to ethnicity, and (d) implications related to leadership and professional preparation for successful multicultural teacher education program.

\section{Implications Regarding Instruments Used To Assess Teachers' Perceptions}

The researcher used quantitative and qualitative methods. A survey and a case study (interviews) were used to collect data for this study with a $96 \%$ response rate on the survey. It is quite interesting to note how participants responded differently on the survey than in the interviews. The researcher concluded from the findings that respondents probably took the 23 items of the questionnaire as a test-taking task and responded thoughtfully. Such data reflect what is inside a respondent's mind, but data can be influenced by both self-awareness and the desire to create a favorable impression (Tuckman, 1999). The scores on this section indicate that the respondents were in high agreement as to their own professional preparation to teach culturally diverse students.

Contradictions were found when participants responded differently to the survey and to the open-ended Question 4 and during the interviews to Question 5. According to Johnson (1998), it is quite likely that the formats of open-ended questions and interviews would elicit responses that arouse feelings and emotions. Writing responses or talking face-to-face is quite like recalling images, emotions, and episodic perceptions that reflect personal ideologies. The researcher has recommended an in-depth study to explain the discrepancies between the qualitative and quantitative findings in this study.

\section{Implications Related To Gender}

The findings of this study indicated overrepresentation of females with $75 \%$ response rate, as is true of the profession. Particularly, female teachers outnumber male teachers in K-12 grades (Johnson, 1998). Is it possible that males consider themselves less competent or overly competent to be teachers and consider teaching to be a female job? This implication suggests further investigation as to why there are more female than male teachers in the K-12 grade schools.

\section{Implications Related To Ethnicity}

Findings indicated that $86.1 \%$ of the respondents were Caucasians, $6.3 \%$ were African-Americans and few respondents were from other ethnicities. The literature review in this study indicates that there is a significant increase in the number of other ethnic groups other than African-Americans in schools in the United States every year. However, there is no increase in the number of teachers from diverse cultural backgrounds. The findings suggest the need for further investigation into the reasons why there is a disproportionate representation of diverse ethnic groups in the teaching profession. The researcher suggests finding ways to encourage people of diverse ethnic backgrounds into the teaching profession. 
Implications Of Leadership And Professional Preparation For Successful Multicultural Teacher Education Programs

The literature review and the findings of this study indicate that universities are not operating from a comprehensive multicultural perspective with regard to teacher preparation programs. Universities and school districts nationwide need to mutually agree upon the definition of multicultural education. University faculties should be culturally diverse to demonstrate how multicultural education and cultural diversity can be effectively incorporated into the curriculum and into the general school environment.

\section{RECOMMENDATIONS}

\section{Recommendations For More Credit Courses In Multicultural Education}

The majority of the respondents to the open-ended Question 4, and case study (interviews) in question 5, strongly recommended more courses in multicultural education, and the inclusion of multicultural topics in other courses. Due to a large influx of culturally and linguistically diverse people in the United States in general and in Northwest Florida in particular, it has become imperative that our teachers are well trained to teach culturally diverse students effectively.

\section{Recommendations For In-Service Workshops In Multicultural Education}

The majority of teachers have very little or no training in multicultural education. Intensive on-going training and professional development through workshops, seminars, cultural exchange programs, visits and study in socially and culturally different countries for teachers are recommended.

\section{Recommendations For Preservice And In-Service Teachers For Real-Life Experiences With Culturally Diverse People}

Volunteering in culturally diverse communities, socializing with an open mind to understand culturally diverse people, and travel to developing and under- developed countries are recommended as worthwhile goals.

\section{Recommendations For Extensive Training In Multicultural Education For Faculty In Teacher Education Programs At The Universities As Well.}

Most respondents during the interviews emphasized that university faculty in teacher education need extensive training in multicultural education, so that they can educate pre-service teachers better.

\section{RECOMMENDATIONS FOR FUTURE RESEARCH} education.

This researcher recommends a number of topics for further study for the advancement of multicultural

1. Similar research studies in the area of teachers' perceptions of professional preparation to teach culturally diverse students should be replicated at several school districts in the country in order to compare and contrast the findings with those of this study.

2. Conduct an in-depth study to find out why participants respond differently to survey as opposed to openended questions and face-to-face interviews.

3. In future research, investigators should observe the teachers in their classrooms to assess their teaching strategies, techniques, and learning environments, and compare these with their responses to surveys and interviews. This might provide the researcher with more accurate data to test the rhetoric against the practice (Howell, 1997).

4. The literature review for this study indicates that there is a significant increase of culturally diverse minority people in other professions in this country. The researcher recommends a study to find out why 
these minorities do not opt for the teaching profession and what can be done to encourage the members of culturally diverse minorities to choose the teaching profession

5. Further research needs to be conducted to find the reasons why there are significantly fewer male teachers as compared to female teachers in the U.S. schools.

6. Findings from the interviews with the participants indicated that the majority of them grew up and went to public schools in Northwest Florida. The majority of teachers also graduated from the University of West Florida's teacher education program. A study is needed to investigate what other universities are offering in the teacher education programs to prepare in-service and preservice teachers to teach effectively in culturally diverse classrooms. Almost 50\% of the teachers in Nodaway school district graduated with their teacher education degree from Northwest Missouri State University, which is the same area in which they were teaching, and the rest came from neighboring counties.

Finally, Banks and Banks (2003) intimated that research studies on teacher education programs that focus on multicultural education are quite limited. Multicultural teacher education occupies a critical position between multicultural theory and multicultural practice. Banks and Banks further cautioned that it is time for multicultural teacher education to assume a proactive leadership role or risk a marginalization that will have dire consequences for the fate of our teachers, our schools, and our nation

\section{REFERENCES}

1. Banks, J. A. \& Banks, C.A.M. (Eds.). (2003). ( $2^{\text {nd }}$ Ed). Handbook of research on multicultural education. New York: Macmillan.

2. Bell, E. D., \& Munn, G. C. (2000). Can we create dreamkeepers for diverse classrooms? (Electronic version). National Forum Journals, 8, 2-9.

3. Bigler, E. (2002). White teachers, race matters: Preparing teachers for the new millennium [Electronic version]. Electronic Magazine of Multicultural Education. 4, 1-10.

4. Blackwell, P. J., Futrell, M. H., \& Imig, D. G. (2003). Burnt water paradoxes of schools of education. Phi Delta Kappan. 84, 356-361.

5. $\quad$ Borg, W. R. \& Gall, M. D. (1989). Educational research: An introduction. New York: Pitman.

6. Chisholm, I. M. (1994). Preparing teachers for multicultural classrooms. The Journal of Education Issues of Language Minority Students, 14, 43-68.

7. Costa, X. B. (1997). Intercultural education: Theories, policies and practices. Brookfield, VT: Ashgate.

8. Fueyo, V., \& Bechtol, S. (1999). Those who can teach: Reflecting on teaching diverse populations. Teacher Education Quarterly, 26, 1-10.

9. Futrell, M. H., Gomez, J., \& Bedden, D. (2003). Teaching the children of a new America: The challenge of diversity. Phi Delta Kappan, 84, 381-385.

10. Gay. G. (1994). A synthesis of scholarship in multicultural education (Urban Monograph No. RI88062012). Oak Brook, IL. North Central Regional Educational Laboratory.

11. Gollnick D. M., \& Chinn, P. C. (2004). Multicultural education in a plural society. (6 ${ }^{\text {th }}$ Ed.). New Jersey and Columbus, Ohio: Pearson Merrill Prentice Hall.

12. Gollnick D. M., \& Chinn, P. C. (1991). Multicultural education for exceptional children. ERIC Digest \# 498. Retrieved June 22, 2002 from http://www.ed.gov/databases/ERIC Digests/ed333620.html

13. Gorski, P. (2000). The challenge of defining a single multicultural education. Multicultural education. Retrieved February 3, 2002 from http://www.mhhe.com/socinece/education/multi/define.html

14. Hinchey, P. H. (1994). Introducing diversity: We don't have to wait for a program. Action in Teacher Education, 16, 28-36.

15. Howell, M. H. (1997). Multicultural teacher preparation: Experiences that affect the perceptions and behaviors of teachers in their ability to embrace diversity. Unpublished doctoral dissertation, University of Massachusetts Amherst.

16. Johnson, G. G. (1998). Teachers' beliefs about being professionally prepared to teach culturally diverse students. Unpublished doctoral dissertation, The Ohio State University.

17. Ladson-Billing, G. (1994). The dream keepers: Successful teachers of African-American children. San Francisco: Jossey-Bass. 
18. Ladson-Billing, G. (1995). Toward a theory of culturally relevant pedagogy. American Educational Research Journal, 32, 670-674.

19. LeCompte, M. D. \& Preissle, J. (1993). Ethnography and qualitative educational research. (2 ${ }^{\text {nd }}$ Ed.). San Diego, California: Academic Press.

20. Marriott, D. M. (2003). Ending the silence. Phi Delta Kappan: 84, 496-497.

21. Merryfield, M. (1995). Teacher education in global and international education. ERIC Clearinghouse on Teaching and Teacher Education Washington DC. (ERIC Document Reproduction Serial No. ED384601).

22. Munn, G. C. (1996). Preparing teachers for a culturally diverse classroom: Multicultural Education for preservice teachers. Unpublished doctoral dissertation, East Carolina University, Greenville, NC.

23. Nelson, T. (2001). Editor's Introduction: Advancing educational opportunities in a multicultural society. Teacher Education Quarterly, 26(3), 147-156.

24. Pallas. A. M., Natiello, G, \& McDill, E. L. (1989). The changing nature of the disadvantaged population: Current dimensions and future trends. Educational Researchers, 18, 16-22.

25. Parla, J.A. (1994). Educating teachers for cultural and linguistic diversity: A model for all teachers. New York State Association for Bilingual Education Journal, 9, 1-6.

26. Pettigrew, T. F. (1979). Racial change and social policy. Annuals of the American Academy of Political and Social Sciences, $441,114$.

27. Pena, R. A. (1997). Cultural differences and the construction of meaning: Implications for the leadership and organizational context of schools. Education Policy Analysis Archives, 5(10), 1-19.

28. Penny, C. M., Forney, A., Harlee, T. M. (2000). Issues challenging education. Preparing educators for multicultural classrooms. Retrieved November 25, 1999 from http://www.horizon.unc.edu/projects/issies/papers/Penny.asp .

29. Sanchez, W. (1995). Working with diverse learners and school staff in a multicultural society. ERIC Clearinghouse American Psychological Association, Washington DC. (ERIC Document Reproduction Service No ED390018).

30. Schlosser, L. K. (1992). Teacher distance and student disengagement: School lives on the margin. Journal of Teacher Education, 43(2), 128-140.

31. Sharma,S. (2005). Multicultural Education: Teachers' Perceptions and Preparation. Journal of College Teaching and Learning, 5(2), 53-63.

32. Tuckman, B. W. (1999). Conducting educational research. Fort Worth, TX: Harcourt Brace College Publishers.

33. U.S. Department of Education. (1990). Twelfth annual report to congress on the implementation of the Education of the Handicapped Act. (ERIC Document Reproduction Service No. ED321513)

34. Wallace, K. R. (2001). Incorporating multicultural/multiethnic topics in teacher preparation. Electronic Magazine of Multicultural Education. 3(2), 1-7. Retrieved December 14, 2001 from http://www.eastern.edu/publication/emme

35. Xu, S.H. (2006). Exploring Diversity Issues in Teacher Education. New Illiteracies in Action.

36. Zeichner, K. M. (1993). Special Report: 16 Key Elements of Effective Teacher Education for Diversity. Educating teachers for cultural diversity (NCRTL special report). East Lansing, MI: National Center for Research on Teacher Learning. (ERIC Document Reproduction No ED 359167). 


\section{NOTES}

